\title{
O Elemento Franco na Coimbra do Século XII: a Familia dos Rabaldes
}

LEONTINA VENTURA

Rabaldo, tal como Artaldo, Arquibaldo, Bernaldo, Ebraldo, Arnaldo, Reinaldo, Geraldo ou Tibaldo' são nomes que só aparecem na onomástica do território portucalense (em especial na fronteira sul) nos últimos anos do século XI oujá no século XII, o que significa que não pertencem ao antigo fundo hispano-godo, provindo, isso sim, de Além-Pirenéus. Afora a composição semelhante do nome $e^{2}$ a todos liga a circunstância de serem cavaleiros. Terão vindo com D. Raimundo ou D. Henrique, sendo alguns deles detentores, tanto de funções militares na fronteira, como administrativas (vicarii, mordomos, juízes).

Todos os francos mencionados são coevos de Rabaldo: Artaldo (1100-1126), Arquibaldo (1110-1127), Bernaldo (1110), Ebraldo (1111 -1129), Arnaldo (1130-1142), Reinaldo (1145-1160), Geraldo (1165) ou Tibaldo (a. 1189).

' São todos antropónimos bitemáticos, sendo, no caso de Rabaldo, formado pelo substantivo hrabn, que significa corvo, símbolo da sabedoria, mais o adjectivo final baldo (tipicamente franco, de origem francesa ou provençal), que significa audaz. Cfr. Joseph-Maria Piel, Estudos de Linguística Histórica Galego-Portuguesa, Imprensa Nacional-Casa da Moeda, Lisboa, [1989], pp. 131 e 140. Ao exemplificar a antroponímia constituída com o nome de corvo, Joseph Piel só aduz como exemplo o nome de Rabaldo para o qual só encontrara atestações para o século XIII, do que conclui que veio de fora. Vindo, com certeza, de Além-Pirenéus, o facto é que terá chegado a Península na década de noventa do século XI. 
Dedicar-me-ei a Rabaldo e sua família, linhagem com forte implantação, ao longo do século XII, nos territórios de Coimbra e Lafões, e que acompanharei até à geração de seus netos (finais do século XII).

\section{Conexões Sociais e Políticas}

É desconhecida a exacta origem e proveniência de Rabaldo, importante cavaleiro de Coimbra e iniciador da família dos Rabaldes. A acreditar na sua origem franca, terá vindo para a Península com D. Raimundo ou, mais provavelmente, com D. Henrique. Era esse um tempo de renovação do conjunto demográfico de Coimbra, com particular incidência do elemento franco ${ }^{3}$. Integrando-se no séquito ou na comitiva de fideles do conde, Rabaldo é, com Artaldo (1100-1126), um dos primeiros a chegar ao território de Coimbra e um dos seus mais estreitos colaboradores. Se este último é referenciado como imperante de Coimbra sub manu de illo comite dom Henrique (1101), mordomo da cidade (1105) e escudeiro de D. Teresa, integrando-se no grupo dos boni homines do concilium de Coimbra, Rabaldo aparece igualmente destacado pelas suas funções político-militaress. Terá, com certeza, substituído alguns quadros deixados vagos pelo afastamento de moçárabes, caso de Martim Moniz, genro de D. Sesnando, de João Gondesendes e outros, sobretudo na zona nais litoral. Através da fidelitas, prestou ajuda militar e assumiu vicarialmente funções de governo com responsabilidades político-militares, fiscais ejudiciais. Promovido social e politicamente, ao ser integrado na cúria vassálica de D. Henrique e D. Teresa, está, desde $1102^{6}$, presente na documentação condal e como vicarius do conde, em Coimbra, em 11097. Nessas mesmas funções, ter-se-á mantido com D. Teresa, a ajuizar por documento desta, de 1113, em que testemunha em primeiro lugar. O facto de exercer funções militares na fronteira e de ser detentor

${ }^{3}$ Os vários contextos da vinda de estrangeiros para Portugal são estudados por Saúl António Gomes, "Imigrantes e emigrantes", in Nova História de Portugal, dir. por Joel Serrão e A.H. de Oliveira Marques, Lisboa, 1996. vol. III, pp. 371 e ss.

+ Cfr. as biografias e quadros genealógicos que já deixámos em Livro Santo de Santa Cruz, ed. de Leontina Ventura e Ana Santiago Faria, INIC, Coimbra, 1990, pp. 51, 63-64 .

Coevo de ambos é ainda Arquibaldo (1110-1127) que casou com Elvira Guterres (1123 Março, DP, IV, 329), que se dividiu entre Coimbra e Viseu, tendo sido mordomo e juiz desta cidade, onde seus filhos João e Mendo Arquibaldes viviam por 1160-1161.

LP 377 (1102 Maio 1).

$L P$ 59. Trata-se do documento de doação do mosteiro de Lorvão à Sé de Coimbra feita pelos condes D. Henrique e D. Teresa, em 29 de Julho de 1109. Note-se que na carta de confirmação, lavrada em Viseu, Rabaldo não está presente, mas está seu filho, Rabaldo Rabaldes. 
de autoridade faz com que o seu nome seja utilizado como elemento de referência importante para certos actos ${ }^{8}$. No entanto, a outorga do foral de Coimbra de 1111, que inviabilizava a detenção de cargos importantes pelos não naturais da cidade, tê-lo-á levado a preferir a zona de Lafões e/ou de Viseu, talvez a zona de origem de sua esposa, e de cujo grupo de barones et infanzones fazia parte em 1117'. Depois disso, não o voltamos a encontrar na documentação. Poderá ter sido morto em algum confronto com os Almorávidas ou, o que é mais provável, a entrega da fronteira de Coimbra a Fernando Peres de Trava terá levado a um ofuscar da família, pelo menos entre 1121 e 1128 . Se D. Henrique privilegiara os conselheiros francos, D. Teresa fê-lo apenas num primeiro momento, porque cedo entregou a condução dos assuntos político-militares e administrativos a barões portucalenses e galegos, em especial aos últimos.

De facto, o filho primogénito de Rabaldo, Rabaldo Rabaldes, que aparece pela primeira vez, em 1109, com a idade de catorze anos, era ainda o pai vigário de Coimbra', só volta a surgir em 1128. Com seu irmão Alvaro Rabaldes, também em Lafões, testemunham a doação de bens em S. Pedro do Sul, feita por Afonso Henriques à Sé de Coimbra". Isto ocorreu na sequência do conflito

' LS 211 (1113 Abr.18): in temporibus domni Rabaldi et judice Gundisalvi Pelaiz. O juiz confirma o documento (único confirmante), faltando, no entanto, a confirmação de Rabaldo, pelo que não deve ter estado presente. Em Abril de 1113, na doação feita à Sé de Coimbra por D. Teresa da ermida de Crestuma (c. Vila Nova de Gaia) e de uma azenha em Coimbra, ele é a $1^{a}$ testemunha ( $L P$ 405). Seria, com certeza, o "fronteiro-mor" da Estremadura que, em 1112, envolvia Coimbra, Viseu e Seia (in Strematura Colimbrie, Viseo et Sena) (cfr. DR 27). Cfr. Leontina Ventura e João Cunha Matos, "Cavaleiros de fronteira (Coimbra, Viseu e Seia) ao tempo de Afonso Henriques", in Actas do II Congresso Histórico de Guimarães "D. Afonso Henriques e a sua Época ", Guimarães, 1997.

' LP 235 (1117 Abr. 8). A referência a Ebraldo, no foral de Coimbra, como um dos representantes do conde $D$. Henrique a quem ele entregara os destinos de Coimbra, e contra o que os munícipes da cidade se haviam revoltado, pareceria mais acertada se recaísse sobre Rabaldo, uma vez que aquele quase não aparece na documentação, o que, para quem detém tais fiunções, será de estranhar. Apenas uma referência, caso do mesmo se trate: testemunha, em 26 de Setembro de 1129, a venda de uma herdade em Fráguas (c. Tondela) feita por Pedro Leovegildes, seus irmãos, sobrinhos, e outros, à Sé de Coimbra (LP 51).

${ }^{10}$ Cfr. nota 7.

${ }^{11} 95$ (1128 Dez. 4). Trata-se da doação de Afonso Henriques à Sé de Coimbra de 4 casais em S. Pedro do Sul. O testemunho de Álvaro Rabaldes, bem como de seu irmão Rabaldo Rabaldes, de Cid Aires e de Mem Afonso só se encontra na lição B deste documento, presente no $L P 63$ e 479. Só uma já comum ligação com o infante Afonso, ou uma relação familiar entre os referidos milites, ou a detenção de bens que confrontam com aqueles casais em questão, justificarão a sua presença. Na verdade, esses casais confrontam com Ansiães, Novais, Pouves, Tabuadelo, Arcozelo, Negrelos e Drizes, sendo que os Rabaldes têm bens nestas últimas quatro vilas referidas. 
que seguramente envolvera o poder político e religioso e a terra de Lafões, ou tão-só o seu tenente Diogo Gonçalves [de Marnel] ${ }^{12}$. Por essa razão o príncipe Afonso confirmará uma propriedade na terra de Lafões, a ele tomada por D. Teresa e pelo conde Fernão Peres de Trava, na pessoa de seu filho Egas Dias e sua esposa Ximena Gonçalves, procurando assim sanar o prejuízo sofrido ${ }^{13}$. Álvaro Rabaldes terá estado também envolvido no conflito com a referida Sé, tendo mesmo chegado a destruir a igreja de Vila Cova ${ }^{14}$, acto que tenta depois reparar ou compensar, em Janeiro de 1133, com a doação de uma propriedade no território de Coimbra ${ }^{15}$. O conflito teve certamente a ver com a entrega, em 1121, do governo de Coimbra a Fernão Peres de Trava, com graves prejuízos para os senhores de Marnel, ao lado dos quais terão estado os francos Rabaldes ${ }^{16}$. As alianças matrimoniais e/ou a detenção de bens nas zonas dos de Marnel justificarão as alianças político-militares, nomeadamente o apoio a Afonso Henriques contra sua mãe e os Travas. Como serão, também, razão para todas estas famílias se integrarem na entourage de Afonso Henriques, depois de este ter conquistado o poder. Terá, por certo, contado com o apoio dos dois irmãos Rabaldes na lide de Ourique ${ }^{17}$. E se de Alvaro Rabaldes não se colhe referência após $1141^{18}$, é possível que Rabaldo Rabaldes tenha morrido durante o ataque

${ }^{\prime 2}$...quia altercatio facta fuit de ipsos casales inter vos et Didacus Gunsalviz qui tunc tenebat terram de Alaphoens (documento citado na nota anterior).

${ }^{13}$ DR 104(1129 Dez. 1).

...pro destruccione illius ecclesie de Villa Cova quam ego destruxi (LP 440).

${ }^{i}$... in illo campo quomodo separat se de Villela usque ad terminum Montemaior (LP440). Estão presentes a este documento Aires Bispo, Mem Pais e Pero castelão (que confirmam), Afonso Pais (talvez o seu cunhado, casado com sua irmã Teresa Rabaldes), Martim Cides, Diogo Goesteiz (que testemunham).

${ }^{16}$ Cfr. José Mattoso, Luís Krus, Amélia Andrade, A terra de Santa Maria nos séculos XI a XIII, Ed. Estampa, 1989, p. 134 e ss; id., A Terra de Santa Maria no século XIII. Problemas e Documentos, Comissão de Vigilância do Castelo de Santa Maria da Feira, 1993, p. 41. Como já disse na nota 11, a presença, em simultâneo, como testemunhas ou confirmantes daquele documento de 1128, de Álvaro e Rabaldo Rabaldes e, bem assim, de Afonso Pais (que virá a casar com Teresa Rabaldes), de Cid Aires (parente, ele ou a sua esposa, da esposa de Rabaldo) e de Mem Afonso de Refóios (que casará com Gontinha Pais,uma sobrinha de Alvaro e Rabaldo Rabaldes) prova bem as relações que já entre todos (e, obviamente, entre eles e o infante Afonso) existiriam e justifica as que, adiante, se desenvolveriam. Há mesmo quem afirme que Álvaro Rabaldes terá sido dos nobres que mais se bateram em 1128 ao lado do infante contra D. Teresa e Fernão Peres de Trava, tendo, por certo, entrado na batalha de S. Mamede, em Junho desse ano (Grande Enciclopédia Portuguesa e Brasileira, vol. 24, p. 162).

As vendas que fazem Rabaldo Rabaldes, em Junho de 1138, a Santa Cruz ( ¿5 131), e Álvaro Rabaldes, antes de Agosto de 1139, a Soeiro Vermudes ( $L S$ 141), poderão indiciar a procura de sustentáculo pecuniário para um conveniente apresto para campanhas em preparação.

${ }^{18}$ Testemunha, em 1141, a carta de couto do mosteiro de Santiago de Sever do Vouga (DR 188). 
do vizir de Santarém a Soure, em 1144, pois seu irmão Pedro, antes de 29 de Julho de 1145, entrega a Santa Cruz os bens que ele, expirando, com a sua alma lhe encomendara ${ }^{19}$.

Se aqueles dois filhos de Rabaldo encontraram junto de Afonso Henriques oportunidade de manutenção de estatuto ou mesmo de alguma mobilidade social, o outro filho, Pedro Rabaldes, logrou essa mobilidade ao serviço da Igreja. Cónego, pelo menos desde 1135, foi bispo do Porto entre 1138 e 1145, tendo sucedido no governo da diocese a D. João Peculiar, a quem porventura o ligavam laços de parentesco ${ }^{20}$. Não deixará de transmitir, mais tarde, o mesmo poder a um sobrinho, Fernando Martins, filho de sua irmã Elvira Rabaldes e de seu primeiro marido Martim Pinioniz.

Desconhecendo com quem casaram Rabaldo Rabaldes e Álvaro Rabaldes, afirmarei, no entanto, que a riqueza e a afirmação da família se fez também à custa da política de alianças matrimoniais. Mais precisamente, através das orientações matrimoniais protagonizadas pelas filhas (ou concertadas para as filhas) de Rabaldo. Todas fizeram bons casamentos, nos quais a diversificação foi a regra: com infanções da terra de Santa Maria, de Grijó ou de Paiva, com infanções do Entre-Douro-e-Minho ou com cavaleiros de Coimbra, todos com o mesmo denominador comum: a pertença à entourage condal ou régia, de D. Teresa e/ou de Afonso Henriques, a que não deixaria de se acrescentar a proximidade geográfica dos respectivos patrimónios familiares. Oportunas uniões conjugais, com recasamentos de quase todas (pelo menos nos casos de Teresa, Elvira e de Maria Rabaldes), que tiveram como resultado a continuidade do pendor político dos filhos e o incremento dos respectivos bens.

Teresa Rabaldes, que terá nascido ainda nos últimos anos do século XI ou nos primeiros do século XII, casou uma primeira vez, antes de Julho de $1115^{21}$, com Gonçalo Gonçalves [de Marnel?], dominus de Lafões ou de Viseu ${ }^{22}$ e

". . .Nam predictus frater meus moriens comendavit se et animam suam et quicquid habehat in manibus meis ( $L S$ 16). Cfr. também LS 225. A data de 29 de Julho de 1145 é a da morte de Pedro Rabaldes. Para correcção da data proposta para o doc. n. $^{\circ} 225$ do Livro Santo veja-se Mário Jorge Barroca, Epigrafia Medieval Portuguesa (862-1422), vol. II, t. I, Porto, 1995, p. 471, nota 98 .

${ }^{20}$ Cfr., por todos, Avelino de Jesus da Costa, "D. João Peculiar co-fundador do mosteiro de Santa Cruz de Coimbra, bispo do Porto e arcebispo de Braga", in Santa Cruz de Coimbra do século $X I$ ao século $X X$, Coimbra, 1984, pp. 59-83. Frei Manuel de Figueiredo, cronista cisterciense, di-lo oriundo de Coimbra e filho de Cristóvão Anes e de sua mulher D. Maria Rabaldes, senhora da vila de Murtede, o que a documentação não prova.

"DP, III, 510(1115 Julho 13), data em que compra, com seu marido, bens em Negrelos.

LP 235:...venerunt ad Viseum insimul ad judicium ante Gundisalvum Gundisalviz et ante Archembaldum qui erat maiordomus Visensis...Trata-se do conflito entre a Sé de Coimbra e os 
vassalo de D. Teresa, e uma segunda vez, antes de 30 de Março de $1131^{23}$, com Afonso Pais de Paiva ${ }^{24}$, vassalo de Afonso Henriques. Nessa altura o príncipe doou-1hes, por certo como dote de casamento, toda a vila de Nespereira, no concelho de Cinfães ${ }^{25}$. Herdada na terra de Paiva, aqui adquire D. Teresa e seus maridos, Gonçalo e Afonso, muitos outros bens, por compra, permuta e encomendação que, juntamente com os que possuía da parte de seu pai e de sua mãe, deixa, em Março de 1138, à igreja de S. João de Almedina, onde se quer sepultar ${ }^{26}$.

Por sua vez, sua irmã Maria Rabaldes, nascida na primeira década do século XII e casada uma primeira vez com um Gonçalo ${ }^{27}$, de quem teve um filho e uma filha ${ }^{28}$, voltou a casar, antes de Julho $1129^{29}$, com Pedro Soares de Grijó,

sobrinhos de João Gondesendes acerca do testamento deste. Veja-se Leontina Ventura, "O cavaleiro João Gondesendes: sua trajectória político-social e económica (1083-1116), Revista de História Económica e Social, 1985, pp. 31 -69, maxime p. 37. Cfr. também DP IV, does. 5 e 7 (respectivamente de 19 de Março de 1116 e de 8 de Abril de 1116), documentos em que é confirmante. Será ainda o mesmo Gonçalo Gonçalves que, em 25 de Janeiro de 1123, testemunha o escambo entre a Sé de Coimbra e Fernão Peres de Trava de uma corte em Coimbra pela vila de Ázere $(L P$ 579) e, a 10 de Outubro de 1123, a doação de Soure aos cónegos Martim Aires e seu irmão Mendo (LP 241). sendo aqui referido como tenente do castelo de Soure. Cf. José Mattoso, Ricos-homens, infanções e cavaleiros, Lisboa, 1982, pp. 185-186.

${ }^{23} \mathrm{DR}$ 116. Talvez tenha mesmo casado antes de Janeiro de 1130 , altura em que confirma a doação de metade de Quiaios, feita por Afonso Henriques a Paio Guterres e sua esposa Urraca Rabaldes. Fa-lo-á tão-só na sua qualidade de cavaleiro de Afonso Henriques, tal como confirma, no mesmo ano, outras doações? Ou como pertencente. por casamento, à mesma linhagem daqueles?

${ }^{24}$ Antes, Afonso Pais fora casado com a moçárabe Argio Zalamiz, com quem, a 1 de Outubro de 1116, vende ao mosteiro de Pendorada bens em Covelo, Oliveira, Seixo e Bolho (c. Cinfães) que haviam sido de Zalama, pai dela (DP, IV, 22). Está presente em documentação de Afonso Henriques, entre 1128 e 1141, na maior parte dos casos a mesma documentação em que estão igualmente presentes Rabaldo Rabaldes e/ou Álvaro Rabaldes, seus cunhados (DR 95, 110, 115, 188).

${ }_{25}$ Este mesmo monarca, antes de 4 de Junho de 1133, doa-lhes uma herdade em Bassim (fr. France, c. Viseu).

${ }^{26}$ Porquê esta doação à igreja de S. João de Almedina e ao bispo de Coimbra (ao tempo D. Bernardo), ao arrepio do que fizeram todos os seus irmãos? Seria Afonso Pais, o segundo marido de Teresa, irmão do anterior bispo de Coimbra, Gonçalo Pais, e este, ainda em vida, teria procurado "atrair" para esta igreja, paço episcopal e "panteão" dos bispos, uma parte dos bens dos Rabaldes? Teresa Rabaldes é também o único membro da linhagem que tem um seu magister, o clérigo Soeiro.

Poderá, porventura, ser o Gonçalo Pais, cavaleiro de Viseu, juiz em 1113 (quando Rabaldo era o dominans), e senhor da terra de Viseu, entre 1125 e 1127. Cfr. nota 8.

${ }^{28}$ A filha, Elvira Gonçalves, refere o irmão, que não nomeia, em documento de Agosto de 1158 em que vende a parte que tem de sua mãe em Lamasma, Arazede, Santa Eulália, no termo de Montemor-o-Velho, em Quinhendros e Treixede, e nas salinas do rio Mondego (LDJT, fl. 153-153v,doc. 308).

${ }^{29}$ A 16 de Julho de 1129, Pedro Soares e sua mulher compram a Trutesindo Mendes a herdade de Murraceses (c. Vila Nova de Gaia), na terra de Santa Maria, pelo valor correspondente a 140 moios, 105 dos quais foram pagos por intermédio de um cavalo (Le Cartulaire Baio-Ferrado du Monastère de Grijó (XI-XII siècles). Paris, 1971, doc. 298). 
filho de Soeiro Fromariques de Grijó, de quem teve Afonso, Paio, Urraca e Teresa Peres ${ }^{30}$.

Urraca Rabaldes, também nascida já durante a primeira década do século XII ou inícios da segunda, casa, pelos finais do ano 1129 ou inícios de 1130 , com Paio Guterres da Silva ${ }^{31}$, tendo recebido de Afonso Henriques, em Janeiro desse ano, talvez como dote de casamento, metade de Quiaios (c. Figueira da $\mathrm{Foz}^{32}$. Fidelis vassalus do princeps Afonso desde que este toma o poder, aquele infanção, já em 14 de Março de 1129, estando em Guimarães, confirma a doação do castelo de Soure aos Templários. Por 1130, terá vindo com Afonso Henriques para Coimbra, tendo-lhe este atribuido a tenência do castelo de Santa Eulália ou mesmo a da fronteira litoral, em substituição de Fernão Peres de Trava ${ }^{33}$. Em Novembro de 1134, Paio Guterres, juntamente com sua esposa Urraca Rabaldes, concederá a Santa Cruz aquela metade de Quiaios (1/4 por testamento e 1/4 por venda), e, em Setembro de 1136, testará ao mosteiro a igreja de S. Mamede da mesma vila ${ }^{34}$. De seu filho Álvaro Pais, maior em 1158, e casado, em Fevereiro de 1176, com Maria Mendes ${ }^{35}$, não se conhece qualquer trato ou proximidade com o poder político. Infere-se daquele documento de 1158 que D. Urraca teria outros filhos, que diz ter compensado com a doação das suas

${ }^{30}$ Deste casamento com Pero Soares de Grijó teria tido não quatro mas cinco filhos, pois sua filha Elvira Gonçalves em documento de Julho de 1160, de venda a Santa Cruz da parte da herdade que teve de sua mãe em Murtede, Raval e Alvade afirma que foram sete os filhos que teve Maria Rabaldes (septem quippe fratres ex ea nati sumus). (Cfr. LDJT, fl. 167v, doc. 340). Cfr. nota 28.

${ }^{31}$ Sobre este Paio Guterres da Silva, veja-se José Mattoso, Identificação de um pais, in Obras Completas. II, pp. 115, 117-119. Segundo o LL58H2, o casamento com Urraca Rabaldes seria o segundo casamento de Paio Guterres da Silva, pois antes havia sido casado com Sancha Anes, de quem teria tido Gomes Pais da Silva, seu sucessor na tenência de Santa Eulália. Recorde-se que, em Dezembro de 1166, Afonso Henriques doa a Santa Cruz o castelo de Santa Eulália, que era préstamo de Gomes Pais da Silva, a quem recompensou com outros bens, sobretudo na zona do Vouga (LDJT, fls. 38-39v, doc. 34). Este aparece ainda em documento de D. Sancho I de Setembro de 1175(?) (DS2).

${ }^{32}$ DR 105 (considerado falso).

${ }^{33}$ Este recebera de D. Teresa, em 3 de Novembro de 1122, o castelo de Santa Eulália e a vila de Quiaios (castrum Sancte Eolalie territorio Colimbrie discurrente rivulo Mondeco... cum suis terminis antiquis et cum Villa Quiayos) em troca do castelo de Coja (LP 560).

${ }^{34}$ TT-Santa Cruz, I, 30.

${ }^{35}$ LDJT, fl 129-129v, doc. 253. Será a Maria Mendes que, em Fevereiro de 1185 , vende a Santa Cruz um casal no lugar de Sanfins, junto a Alcofra, no território de Lafões (TT-Santa Cruz, XI, 18)? Mais uma vez Alcofra, que se liga de imediato a Cid Aires, nos faz pensar em qualquer parentesco entre este e a linhagem dos Rabaldes. Ximena Cides, que presumo ser filha de Cid Aires (o de Alcofra), foi casada em primeiras núpcias com um Mendo de quem teve Mendo Mendes. Seria sua filha aquela Maria Mendes? 
arras, em Mira e outras partes, pela cedência que fez de bens a Santa Cruz. O $L L 58 \mathrm{H} 2$ e 58V3, omitindo aquele Álvaro Pais, refere como sua filha Gontinha Pais que diz ter casado, sucessivamente, com Pero Oriz e com Mem Afonso de Refóios ${ }^{36}$, de quem terá tido Garcia Mendes de Parada. Mem Afonso de Refóios está de facto casado com uma Gontinha Pais, entre 1144 e $1160^{37}$. No entanto, esta surge identificada como Gontinha Pais de Vouga ${ }^{38}$ e não da Silva, o que poderá decorrer do facto de não ter quaisquer bens na região de origem de seu pai mas tão-só nas zonas onde sua mãe era herdada. Teria casado com cerca de catorze anos, por Novembro de 1144, altura em que a Sé de Coimbra concede ao casal umas casas dentro da cidade, em frente à canónica, por um preço muito abaixo do seu real valor, mas tendo em conta o serviçojá recebido desse nobre (estimantes dileccionem, auxilium et consilium vestrum) e o que ainda deles esperavam (ut quandiu vixeritis fideles, adjutores et obedientes) ${ }^{39}$.

Elvira Rabaldes casou, primeiro, com Martim Pinioniz ${ }^{40}$ e, depois, com o alcaide de Coimbra Rodrigo Pais. Do primeiro teve quatro filhos

${ }^{36}$ Este é um fiel vassalo de Afonso Henriques, que já teria estado ao seu lado no conflito com a mãe D. Teresa, e que está na corte desde 1128 até $1160(D R$ 95, 123, 158, 171, 179, 194, 201, 224, 229, 232, 234, 247, 275). Aparece, algumas vezes, com cargos na corte ou na casa do rei: dispensator (DR 171, 1139), speculator (DR 179, 1140), dapifer (DR 194, 1142). Tinha em préstamo o castro de Arouce (DR 247, 1154 Abril 30).

Assim sendo, terá sido em segundas núpcias que Gontinha Pais casou com Pedro Oriz, e não em primeiras como afirma o Livro de Linhagens do Conde D. Pedro (58 H3 e V3). Além de que a idade dela o não permitia, pois não teria mais de 14 anos quando casou com Mem Afonso Pedro Oriz, que aparece na documentação entre 1163 e 1207, parece estar viúvo em Dezembro de 1164. Nesta altura, juntamente com seus filhos, Godinha Peres (com seu marido Pedro Pais [Albougia]), João Peres e Pedro Peres vendem ao bispo de Coimbra uma casa na freguesia de S. João de Almedina (Sé de Coimbra, VI, 26; LP 557). Aparece na corte entre 1171 (DR 309) e 1191 ( DS 12, 13, 19, 30, 31 e 53). Surge como testemunha ou referido como proprietário, em Maio de 1195 (S. Jorge, IV, 39), Março de 1196 (S. Cristóvão, cx. 9, m. I, n 18) e Maio de 1207 (S. Cristóvão, cx. 9, m. II, $n^{\circ}$ 3), in João da Cunha Matos, A Colegiada de São Cristóvão de Coimbra (séculos XII e XIII), Tomar, 1998, docs. 40 e 50. Nunca é referido com qualquer esposa, muito embora, salvo aquele documento de 1164 , justificado ou pela sua recente viuvez e consequente partilha de bens ou pelo casamento de sua filha, apareça sempre como testemunha.

${ }^{38}$ TT-Colegiada de S. Cristóvão de Coimbra, cx. 9, m. I, n 4 (1152 Jan. 27), in João da Cunha Matos, A Colegiada de São Cristóvão..., doc. 15. Trata-se de uma compra que faz Mem Afonso e sua esposa de um casal em Taipa e meio casal em Travasso (c. Oliveira de Azeméis).

${ }^{39}$ LP 387. Não podemos esquecer que era então prior da Sé de Coimbra D. João [Anaia], irmão de Martim Anaia que era casado com Elvira Afonso de Refóios, irmã de Mem Afonso.

"Será com certeza o Martim Pignuniz que, em 18 de Julho de 1131, testemunha a doação de S. João do Monte (c. Tondela) a Mestre Garino e seus freires (DR 118), o que justificará a detenção de bens na terra de Besteiros por parte de D. Elvira Rabaldes (LS 28 e 136). Era, por certo, irmão ou familiar de Paio Pinioniz que, em 1124, é referido como proprietário na terra de 
(Fernando ${ }^{41}$, Paio, Pedroe Teresa Martins) e do segundo, cinco (Afonso, Fernando, Gonçalo, Sancha e Urraca Rodrigues). Martim Pinioniz era, muito provavelmente, filho do mandante da terra de Lafões, Piniolo Garcia (1060-1095) ${ }^{42}$ Rodrigo Pais, com quem Elvira Rabaldes casou antes de Setembro de $1145^{43}$, era, ao tempo, o cavaleiro mais importante de Coimbra (dux militum Colimbrie, princeps Colimbrie), exercendo as funções de alcaide da cidade pelo menos desde 1137 e até 1156 ou $1151^{44}$. Auxiliou Afonso Henriques na conquista de Lisboa, fazendo, em Outubro de 1147, testamento a Santa Cruz da sua vila de Oliveira de Frades, concedida jure hereditario por Afonso Henriques ${ }^{45}$, e, logo a seguir à conquista, a 1 Novembro de $1147^{46}$, vê-se recompensado pelo rei, que lhe vende a herdade de Podentes (c. Penela), pro multo bono servitio e 150 morabitinos. Recompensa para o mesmo serviço talvez tenha sido a doação de bens em

Paiva (TT-Tarouquela, II,2) e, em 27 de Maio de 1128, ao lado do infante Afonso, confirma a carta de couto outorgada à Sé de Braga por Afonso VII e sua mãe D. Urraca (DR89); e de Mendo Pinioniz que, embora já se encontre documentado em 1121 -1123 (DP, IV, 203 e 343), em Setembro de 1145 aparece ao lado de D. Rodrigo e D. Elvira (cf. infra nota 43). Talvez fosse também seu irmão o Miguel Pinoniz referido em documento de Agosto de 1168, como proprietário (ou sua esposa) em Requeixada (LP 375). Era, seguramente, sua irmã Ouroana Pinioniz a quem Fernando Martins, bispo do Porto, trata por sua amita (não amica como se transcreve no Censual do Cabido da Sé do Porto, Porto, Imprensa Portuguesa, 1924, p. 388).

${ }^{4}$ Como já referi anteriormente, Fernando Martins foi bispo do Porto (1176-1185). É, decerto, o que aparece, já como deão, em Abril de 1170, a testemunhar o testamento de sua irmã Teresa Martins a Santa Cruz (LDJT, fl. 70-70v, doc. 104), tendo morrido a 8 de Novembro de 1185 (Censual..., pp.385-389).

${ }^{42}$ Muito embora só em documento de 1070 Piniolo Garcia apareça expressamente como mandante Alahouneis, creio que o terá sido desde a Reconquista da região. Cfr. DC 423 (1060), 475 e476 (1069), 490 (1070 Maio 1), 823 (1095). Piniolo Garcia era filho de Garcia Pinioliz e de Ledegundia (DC 382, de 1052).

Se não constituem dote de casamento, no todo ou em parte, os bens que, em Abril de 1142, Afonso Henriques lhe doa expressamente como recompensa para seus serviços vassálicos, em Assamassa, Requeixada, Sujeira e Coselhas (c. Coimbra) e Alcabideque (c. Condeixa) (DR194), talvez o tenha constituído a doação da vila de Oliveira de Frades, cuja data se desconhece. A data acima referida, de Setembro de 1145, reporta-se a um documento de Santa Cruz (TT-Santa Cruz, II, 39) onde estão presentes D. Rodrigo Pais e sua esposa Elvira Rabaldes, para além de Mendo Pinioniz (que pode ser cunhado dela, pelo primeiro casamento) e sua esposa Elvira Gonçalves (que pode ser sobrinha de Elvira, filha de sua irmã Maria Rabaldes).

"A posição hierárquica em que aparece é clara: dapifer curie, vexillifer curie, subdapifer, dux militum Colimbrie. Cfr. DR 141 (de 1134, considerado falso), 161, 168, 171, 182, 192, 193, 196, 199, 200, 201, 206, 216, 217, 224, 225, 232, 234, 235, 239, 240, 242, 243, 246, 247, 251, 257. No seu testamento, de 1159 , refere-se como alcaide de Coimbra, o que prova que, deixado o cargo, se mantém a honra. $O$ mesmo acontece com o alcaide Cerveira que, mesmo depois de ter deixado o cargo, não é referido por outra forma que não seja alcaide Cerveira.

4s LS47.

${ }^{4}$ DR 224. 
Torres, no Furadouro de Tamugia, no actual concelho de Torres Vedras, que os seus filhos, Afonso e Fernando, vendem a Santa Cruz, em Julho de $1175^{47}$. Chegou a ser alcaide (prefectus ou pretor) de Lisboa em Março de $1158^{48}$.

Na terceira geração, a dos netos de Rabaldo, são os filhos de Elvira Rabaldes e de Rodrigo Pais que, não dando continuidade ao nome, mantêm algum influxo político. Afonso Rodrigues e Fernando Rodrigues são cavaleiros do exército régio, integrando-se, tal como seu avô e seu pai, no grupo dominante da cidade de Coimbra ${ }^{49}$. Começam a aparecer, juntamente com seu pai, na corte de Afonso Henriques, em $1156^{50}$, tendo pouco mais de catorze anos. Continuarão a estar presentes, ainda que muito mais esporadicamente que seu pai, até $1163^{\text {s1 }}$; embora fora da corte, Afonso Rodrigues continua a aparecer até 1176, e Fernando Rodrigues até 1190. O seu irmão Gonçalo Rodrigues seria igualmente cavaleiro do exército régio, e, se bem que nunca apareça em documentação régia ${ }^{52}$, sabe-se

"LDJT, fl. 97v, doe. 177. Há quem sugira que o topónimo Ribaldeira, na fr. de Dois Portos (c. Torres Vedras), seria originariamente Rabaldeira, derivado do antropónimo Rabaldo (Cfr. Grande Enciclopédia Portuguesa e Brasileira, vol. 32, p. 279). De facto assim se chamava no primeiro quartel do século XIII, pois em documento do mosteiro de S. Paulo de Almaziva, lavrado em Torres Vedras, a 5 de Abril de 1221, entre as várias testemunhas, está João Calvo de Rabaldeira (Maria José Azevedo Santos, O Cartulário de S. Paulo de Almaziva, Coimbra, 1981, doc. 14, p. 44). Por outro lado, a 14 de Junho de 1300, a rainha D. Beatriz, viúva D. Afonso III, doa à Ordem de Santiago a sua quintã da Rabaldeira (cfr. Leontina Ventura, A Nobreza de Corte de Afonso III, Coimbra, 1992 (dissertação de doutoramento), $2^{\circ}$ vol., p. 530). A ser assim, Rodrigo Pais com sua esposa e seus filhos teriam, na sequência da conquista de Lisboa, participado no repovoamento da região de Torres Vedras e deixariam o nome de Rabaldo ligado à toponímia. Outros, todavia, colaboraram nessa tarefa, porquanto a herdade que os filhos de Rodrigo Pais vendem a Santa Cruz confronta: a norte, com herdade de Santa Cruz; a ocidente, com João Aires; a sul com Gonçalo Capelo e com D. Ramiro.

${ }^{4}$ DR 268, 269.

${ }^{4}$ Cfr. José Mattoso, Ricos-homens, infanções e cavaleiros, pp. 184, 185 e 190.

${ }^{\text {so }}$ DR 257 [ 1156-1157]: carta de doação de casas e terras em Sintra a Mestre Gualdim Pais.

${ }^{51}$ Afonso Rodrigues testemunha, em Março de 1162, a doação da mata de Aljazede ao mosteiro de Santa Cruz (DR 280) e, em Fevereiro de 1163, a concessão do eclesiástico de Alcanede (c. Santarém) ao mesmo mosteiro (DR 285). Num caso como no outro estão também presentes seu cunhado Pero Pais (casado com Sancha Rodrigues) e o tio Pedro Randulfes (irmão de Mor Randulfes, mãe daquele Pero Pais).

Sabemos que ainda está vivo em Março de 1162, altura em que, com seus irmãos Afonso e Fernando e seu cunhado Pedro Pais (casado com Sancha Rodrigues), confirma a carta de liberdade do mosteiro de Santa Cruz, concedida pelo bispo de Coimbra, D. Miguel Salomão (LDJT fl. 20v-22, doe. 14). O tempo que se seguiu, até finais da referida década de 60, foi marcado por intensa actividade bélica: sem falar na guerra com Leão, são de relevar as sucessivas campanhas militares e significativas conquistas que alcançam praticamente todo o Alentejo (Alcácer do Sal, Évora, Beja, Elvas, Juromenha), chegando mesmo a penetrar nas áreas da 
que foi morto, antes de Fevereiro de 1168, pelos sarracenos ${ }^{53}$. À semelhança do que occorreu na geração anterior, um outro elemento da família fez carreira na Igreja: Fernando Martins, meio irmão de Fernando, Afonso e Gonçalo Rodrigues, criado por Cid Aires $^{54}$, chegou a ser bispo do Porto entre 1176 e 1185.

Não se conhecendo os casamentos de Afonso e Gonçalo Rodrigues, sabe-se, no entanto, que Fernando Rodrigues casou com Elvira Peres, sobrinha materna de D. Pedro Mendesss e paterna de Ermígio Ramires, Fernando Ramires e Gontinha Ramires ${ }^{56}$. De seus meios irmãos Paio e Pedro Martins, só se conhece o casamento do primeiro com Elvira Hourigues (1170). Quanto à sua irmã, Teresa Martins, casou com Gualter, de quem teve Pedro Gualter, contemplado no testamento de seu tio, o bispo do Porto, Fernando Martins ${ }^{57}$. As irmãs de Fernando e Afonso Rodrigues, Sancha (1157-1204) e Urraca (1162-1174) fizeram bons casamentos. Esta última casou-se duas vezes, uma com Martim Gonçalves e outra com Mem Peres Clavo. Se bem interpreto a venda que Urraca Rodrigues e seu segundo marido fazem a Santa Cruz, em Novembro de 1174, de uma herdade de seu património e matrimónio em Raval, por 25 morabitinos mais a herdade de Tavares que fora dada por alma de seu sogro Pedro Clavo ${ }^{58}$,

"Reconquista" leonesa (Cáceres, Trujillo e outras praças a leste do Guadiana, envolvendo a cidade de Badajoz). (Cfr. Nuno Pizarro Dias,"Uma monarquia de sucesso", in Actas do II Congresso Histórico de Guimarães "D. Afonso Henriques e a sua Época", Guimarães, 1997). Gonçalo Rodrigues poderá ter morrido numa dessas campanhas do Alentejo. Certamente que seus irmãos partiram para as mesmas campanha, como faz crer a venda que faz Afonso Rdrigues a Santa Cruz, em Março de 1162, em troca de dinheiro e de um cavalo (cfr., infra, nota 77). Terão tido melhor sorte!...

${ }^{s 3}$ LDJT fls. 64v-65v, docs. 89 e 91. Seus irmãos Afonso, Fernando, Urraca e Sancha Rodrigues fazem testamento a Santa Cruz de dois casais em Lafões, na vila de Drizes, e de metade de uma vinha em Coimbra (em Assamassa), pro anima fratris nostri Gunsalvi Roderici cujus fuerunt qui occisus est a Sarracenis.

${ }^{54}$ No seu testamento, Fernando Martins deixa a João Cides (presbítero e capelão de Santa Maria de Coimbra e cónego do mosteiro de $S$. Jorge desta cidade) a herdade em Lafões que lhe tinham deixado os pais dele, seus nutritores (Censual..., p. 385).

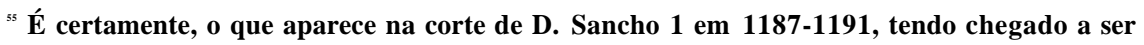
seu dapifer (1191) DS 17, 36, 50, 51, 53-57.

${ }^{56}$ É a D. Elvira Peres, prima direita de D. Pedro Fernandes de Paiva ou de Portugal, ao qual deixa seus bens de herança, em 1203, uma vez que não tinha descendência (TT-Tarouquela, m. V, doc. 4). Seus tios paternos são, respetivamente, casados com Elvira Sarracines, Cristina Soares de Paiva e Egas Moniz de Urtigosa.

${ }^{57} \mathrm{O}$ casamento de Teresa Martins com Gualter está confirmado por documento de Santa Cruz de Abril de 1169, altura em Gualter já teria desaparecido (LDJT, fl. 70v, doc. 104). É certamente o Gualter senhor de Gouveia que, em Novembro de 1140, confirma a doação e couto da vila de Aldião (c. Gouveia) aos irmãos Garcia e Paio Eneguiz (LS 52=DR 181).

${ }^{s s}$ LDJT fl. 138, doc. 272. 
com este ou com seu filho se iniciaria a linhagem dos milites de Tavares. Quanto a Sancha Rodrigues, casou depois de Abril de $1157^{59}$ com Pero Pais (neto de Randulfo Soleimás, moçárabe de Coimbra, e filho de sua filha Mor Randulfes), documentado na corte de Afonso Henriques entre 1156 e $1163^{60}$. Sancha Rodrigues tomará hábito em Santa Cruz, decerto após a morte de seu marido ${ }^{61}$, ocorrida antes de Fevereiro de $1165^{62}$. A filha do casal, Elvira Peres, casa com Martim Viegas de Podentes (1193-1208), aqui se iniciando a linhagem dos milites de Podentes.

\section{Construção e desagregação de um património}

Embora não haja sobre Rabaldo, além de um documento em que é referenciado em confrontações de bens ${ }^{63}$, qualquer outro em que não figure como confirmante ou testemunha, quer em documentação da Sé de Coimbra, quer dos condes D. Henrique e D. Teresa, certamente que o serviço público referido se traduziu em poder económico nas zonas onde o exerceu. Por presúria, doação e/ou compra, deteve algumas villae ou partes de villae nos territórios de Montemor-o-Velho e Santa Eulália (Arazede, Treixede, Lamasma e Santa Eulália), em Cantanhede (Murtede, Enxofães), em Anadia (Aguim) e no Campo

${ }^{\text {s9 }}$ Nesta data, a mãe de Pedro Pais, Mor Randulfes, com seus filhos Justa Pais (casada com Fernando Gonçalves), Pedro Pais e Simão Pais vendem a Santa Cruz a duodécima parte da vila de Murtede e a sua parte da vila de Enxofães, por 40 morabitinos (LDJT, fl. 167-167v, doc. 339). A colocação de Pedro Pais, em segundo lugar, após sua irmã, porque casada, prova que ele ainda o não estava.

${ }^{60} \mathrm{O}$ facto de, desde 1156, para além de Rodrigo Pais e Randulfo Soleimás se encontrarem ainda na corte de Afonso Henriques, começarem a aparecer também Afonso e Fernando Rodrigues, filhos do primeiro, e Pedro e Simão Pais, netos do segundo, ajuda a explicar as alianças matrimoniais concertadas.

${ }^{61}$ Se a ligação entre a família dos Rabaldes e a de Cid Aires é tão próxima quanto penso, o facto de a filha deste, Ximena Cides, ter professado em Santa Cruz em Julho de 1175 (LDJT, fl. 193v, doc. 379), poderia ter induzido Sancha Rodrigues a fazê-lo também, se o não fez ela primeiro.

${ }^{62}$ Cfr., infra, nota 79. Este reduzido tempo de matrimónio (1257-1263/65), tendo em conta que Sancha Rodrigues sobreviverá ao marido mais 40 anos, leva a crer que a morte dele se tenha ficado a dever a um qualquer acidente guerreiro, sendo que nos levaria a colocá-lo numa data aproximada, se não a mesma, à que morreu Gonçalo Rodrigues seu cunhado.

${ }^{6}$ LS 146 (1132 Fev.). Refere-se, aqui, uma terra que foi de D. Rabaldo, situada a sul de uma propriedade de João Mendes e de sua mulher Urraca Pais, no campo que se chama Calimbriam juxta illos occulos de Calimbria. Para uma correcta localização dos bens que esta família tem, nos territórios de Coimbra, Montemor e Santa Eulália, veja-se Jorge Alarcão, In territorio Colimbrie: lagares velhos (e, alguns deles, deslembrados) do Mondego (trabalho ainda inédito que o autor, gentilmente, pôs à minha disposição). 
de Coimbra (Alvade, Raval e Fontoura), onde seus filhos serão herdados. Precisamente onde D. Sesnando e a maior parte dos seus fideles os tiveram, o que significará que seriam terras adscritas ao poder régio, concedidas como benefícios em troca de serviço militar.

Do mesmo modo, o desempenho de idênticas funções na fronteira beirã, o casamento e/ou a presumível transferência para a zona de Lafões deram origem, nessa região, a novas presúrias, aquisições ou doações de bens. A detenção por seus filhos de partes equitativas desses bens é a prova de que aí os tinham herdado e de que os vários casamentos efectuados entre as filhas de Rabaldo e os cavaleiros dessas paragens foram impulsionados tanto pelo prestígio político-social da família dos Rabaldes como pela proximidade e importância de seus patrimónios. Arcozelo, Tabuadelo, Pinho, Manhouce, Pindelo, Drizes, Moure, Covelo, S. Martinho das Moitas, Negrelos, Estrada (c. S. Pedro do Sul) Pinheiro de Lafões (c. Oliveira de Frades), Campia, Cambra, Cercosa, Santa Comba, Paredes, Caveirós de Cima (c. Vouzela), são alguns dos muitos bens que detém na referida zona ${ }^{64}$.

Nada se sabe sobre sua esposa e o seu estatuto, tão-só que era proprietária em Aguim, como o afirmam suas filhas Elvira e Urraca Rabaldes ${ }^{65}$. Mas, como

${ }^{64}$ Ainda em 1258 (segundo as Inquirições) a Sé do Porto tinha 4 casais em Negrelos, doados pelo bispo do Porto D. Pedro Rabaldes, e 2 casais em Mourel de doação do bispo do Porto Fernando Martins.

${ }^{\text {"s }}$ LS 136 e 137. A detenção destes bens em Aguim, de uma grande parte do património no território de Lafões e o balancear entre este território e Coimbra, permite-nos pôr a hipótese de parentesco entre a mulher de Rabaldo e Cid Aires (natural de Santa Maria da Várzea). Tal como este, também Teresa Rabaldes tem uma corte dentro da cidade de Coimbra. Seja-nos permitido remeter para o nosso artigo "As cortes ou a instalação em Coimbra dos fideles de D. Sesnando". a publicar em volume de homenagem ao Prof. José Marques, pela Faculdade de Letras do Porto. Com alguma probabilidade de ser esposa de Rabaldo se apresenta a Goncinha Gonçalves que, em 1138. faz também testamento a Santa Cruz da herdade que tem em Aguim. Este testamento é confirmado por D. João Peculiar, bispo do Porto, e testemunhado por Pedro Rabaldes, o que, se se não explica por razões de jurisdição eclesiástica, justificar-se-ia por razões de parentesco (LS18). Esta Goncinha Gonçalves faz também testamento a S. Salvador de Grijó de bens em Cabanões e em S. Miguel de Travassô, em Dezembro de 1142 e em 1143, referindo-se, sem os nomear, a filhos e netos (Baio-Ferrado de Grijó, docs. 30 e 32). Não deixarei, porém, de chamar a atenção para o documento de Agosto de 1139 referido na nota 17, onde se diz que a propriedade que Soeiro Vermudes e suas filhas vendem a Santa Cruz e que haviam comprado a Álvaro Rabaldes fora de D. Boa, deixando pensar que esta seria a mãe de Álvaro. Trata-se de D. Boa casada com D. Cipriano, que deve ter tido toda a região litoral (Santa Eulália, Lamasma, Alhadas, Arazede) em préstamo de D. Sesnando. A mesma referência lhe faz, em Abril de 1159, o João Mides casado com Maria Sarracines, ao vender aí bens a Santa Cruz (TT- Santa Cruz, m. IV, doc. 29; LDJT, fl. 153, doc. 307). 
se sabe, foram pelo menos sete os filhos que, equitativamente ${ }^{66}$, herdaram os seus bens: Álvaro Rabaldes, Pedro Rabaldes, Rabaldo Rabaldes, Elvira Rabaldes, Maria Rabaldes, Teresa Rabaldes e Urraca Rabaldes ${ }^{67}$. Ampio património territorial composto por herdades diversas - de carácter agro-pecuário e marítimo (salinas) - e dispersas que, mercê da organização do parentesco, bilateral e cognática, no que respeita à transmissão do património, e a um elevado índice de fertilidade da família, se foi tornando menos significativo. Muitos bens, mas poucos para tantos filhos; por isso, foram em parte testados e em parte vendidos ao mosteiro de Santa Cruz, assim se desagregando o dominio fundiário de Rabaldo. As filhas, e seus maridos, não deixaram de se esforçar por aumentar os seus domínios fundiários, comprando novas terras ou procurando escambos vantajosos. À excepção de Teresa Rabaldes, que deixa os seus bens à igreja de S. João de Almedina, onde se manda sepultar, cada um dos seus irmãos testa uma pequeníssima parte, vendendo a maior fatia dos seus bens a Santa Cruz, aí escolhendo sepultura. Esses bens voltam a reunir-se e a avolumar-se, no senhorio de Santa Cruz, redobrando de valor e importância.

Tal é a sua relevância, que é sobretudo através da documentação do mosteiro de Santa Cruz que se pode reconstituir esta família. A sua inclusão nos Livros de Linhagens ocorre apenas por via do casamento de uma filha de Rabaldo, Urraca Rabaldes, com Paio Guterres da Silva (LD18J2; LL 58H2) e de Maria

${ }^{6}$ A título de exemplo, cada um dos filhos de Rabaldo tinha 1/12 de Murtede.

"7 Em 1 de Novembro de 1102 está documentado um Mendo Rabaldes que testemunha a venda de uma herdade em Vila Nova (c. Coimbra) (TT-S. Jorge, 1,2). Pela data só poderia tratar-se de um filho de Rabaldo, embora, a sê-lo, teria de ser de um casamento feito antes de ter vindo para a Península. Como não volta a surgir, talvez tenha desaparecido e, por isso, não divide depois os bens com seus irmãos. É estranho, todavia, nunca ter sido por eles referido. Afonso Rabaldes é referido por Rui de Azevedo para o ano de 1123 (DR I, tomo 2, p. 653). Um Domingos Rabaldes que, com sua mulher Maria Martins e seus cunhados, vende bens em Taveiro ao mosteiro de S. Jorge, em Março de 1174 (TT-S. Jorge, IV, 5), se é da família, a ajuizar pela data, só poderá ser filho de Rabaldo Rabaldes. Também em documentos de Agosto de 1153 ( $L S$ 168 e LDJT fl. 104-104v.,doc. 192) e Maio de 1168 (LDJT, fls. 117v-118, doc. 227) testemunha um Rabaldo que não pode ser nenhum dos Rabaldes em análise. Curiosamente, os que, neste último documento, vendem porções de uma vinha além Mondego a Santa Cruz são descendentes de francos (netos de Perrot e filhos de João Perrot que tinha comprado metade desa vinha ao rei D. Afonso, por dezoito morabitinos). Mário Jorge Barroca (op. cit., pp. 470-472), ao estudar o epitáfio da primeira prioresa do mosteiro de Cheias, D. Justa Rabaldes, aceita que esta seja filha de Rabaldo. Teria saído do mosteiro feminino de São João das Donas, junto a Santa Cruz, para ir para o mosteiro de Cheias, restaurado pouco depois de 1147. A falta de documentos relativos a este tema, não permite confirmar ou infirmar tal hipótese. Apesar de nunca ser referida por qualquer irmão, o facto de, após a conquista de Lisboa, alguns elementos da família se terem estabelecido em Lisboa e Torres Vedras, confere alguma probabilidade à hipótese. 
Álvares, filha de Álvaro Rabaldes, com Nuno Gomes Guedeão, pais de Pero Nunes Pestanas de Cão (LD 6T6). Por outras palavras, embora sediada em Coimbra, a família não deixou de se aliar, ao tempo de Afonso Henriques, com famílias do Entre-Douro-e-Minho, ficando o seu registo, por intermédio destas ligações, incorporado na obra genealógica.

É, porém, no cuidado posto por Santa Cruz no reforço da segurança dos seus bens e interesses que surpreendemos a perpetuação da memória dos benfeitores (benefactorum digne memorie recordatio). Recordatio, agora essencialmente de natureza económica, ligada à necessidade provatória da origem dos direitos e do património adquirido. Assim, a II Parte do Livro Santo de Santa Cruz, intitulada "Livro dos Testamentos dos cónegos de Santa Cruz e dos homens de Coimbra", tem como segundo documento o testamento de Maria Rabaldes e de Pedro Rabaldes (em nome de seu irmão Rabaldo Rabaldes). Ela deixa o que tem em Murtede, e ele o que seu irmão, à hora da morte, lhe encomendara, em Lamasma, Arazede, Santa Eulália e Treixede. Analisando bem o título da referida parte do Livro Santo e sabendo que este se começa a escrever em $1155^{68}$, concluir-se-á que os filhos de Rabaldo, sessenta anos depois de este ter vindo para a Península, são já reconhecidos como homines colimbrienses. A colocação deste documento, de Março de 1147, em segundo lugar, entre um de 1132 e outro de 1133, dará conta da importância destes bens para Santa Cruz. Distribuídos os documentos segundo a sua natureza jurídica (testamentos ou doações e vendas) e, dentro deles, por um critério geográfico, segue-se depois uma hierarquia que espelha uma lógica de poder. Sendo do mesmo ano (de Outubro) o testamento da vila de Oliveira de Frades feito por Rodrigo Pais e sua esposa Elvira Rabaldes, este ocupa na mesma II Parte do Livro Santo, o n ${ }^{\circ} \mathrm{XXXV}$, o que prova uma menor importância destes bens para o mosteiro ${ }^{69}$, situados em zona mais periférica e isolada da sua mancha patrimonial ${ }^{70}$.

"Cfr. Leontina Ventura "Introdução", in Livro Santo de Santa Cruz, ed. de Leontina Ventura e Ana Santiago Faria, INIC, Coimbra, 1990, p.36.

${ }^{\circ}$ LS 47. Não está sequer presente no Livro Santo a confirmação deste testamento, ou alargamento dele, feita em Maio de 1149 (TT-Santa Cruz, III, 20), onde, além de Santa Cruz, são contempladas várias outras instituições (igreja de Santa Maria de Vouzela, ordens do Templo, do Hospital e de S. João) e obras de assistência (remissão de 10 cativos, vestir 30 pobres cum capis et sais e dar refeição, três vezes por ano, a pobres, devendo-se, em cada uma delas, gastar 2 vacas, 20 carneiros e pão e vinho com abundância). A riqueza que sustentaria estas obrigações e que está subjacente à doação testamentária feita por Rodrigo Pais a Santa Cruz traduz claramente o poder económico de que este seria detentor.

${ }^{70}$ Havia recebido apenas uma outra herdade neste concelho em Janeiro de 1139, da parte de Telo Mendes ( $L S_{41}$ ), não tendo o mosteiro aí efectuado qualquer compra. Cfr. mapa e quadros de compras e doações presente no Livro Santo de Santa Cruz de Coimbra, ed. de Leontina Ventura e Ana Santiago Faria, INIC, Coimbra, 1990, pp. 385 e ss. 
Do mesmo modo, na I Parte do "Livro das Vendas de Coimbra, Montemor, Quiaios, Cadima e Mira", após três documentos fundamentais relativos à aquisição dos terrenos para implantação do mosteiro de Santa Cruz (de 1130, 1131 e 1133$)^{71}$, seguem-se 12 documentos de 1134-1148, que são precisamente as cartas de venda de propriedades ao mosteiro de Santa Cruz por parte de filhos de Rabaldo ${ }^{72}$. Venda ou simples entrega, para pagamento de uma dívida, de um empréstimo contraído, ou ratificação de uma entrega anterior, feita a título de penhor por uma quantia pecuniária solicitada ao mosteiro. A situação difícil a que chegara esta numerosa família, tendo necessidade de se endividar para com o mosteiro, e a pressão que este exerceu sobre ela e os demais que tinham propriedades nas mesmas zonas, estão em íntima correlação. Passaram para o mosteiro de Santa Cruz as herdades de património que possuíam no Campo de Coimbra, em Alvade e Raval; em Lamasma, Eimede, Santa Eulália, Maiorca (c. Figueira da Foz); Arazede, Treixede, Quinhendros, Reveles (c. Montemor-o-Velho), em Enxofães e Murtede (c. Cantanhede) e em Aguim (c. Anadia).

É ainda em documentação avulsa de Santa Cruz ou no Livro de D. João Teotónio, que dá seguimento ao Livro Santo ${ }^{73}$, que, pelos anos 1158 e 1159 , deparamos com Urraca Rabaldes e Rodrigo Pais com sua mulher Elvira Rabaldes, transferindo para Santa Cruz outros bens, principalmente na zona de Lafões. Uma menor apetência de Santa Cruz por estas zonas (onde tinha menos bens e onde havia uma grande implantação da Sé de Coimbra) fez decerto retardar a entrega até à hora da morte ejustificará que, em parte ou no todo, sejam doados e não vendidos. É óbvio que, neste último caso, a necessidade económica não se fazia sentir, comojá se provou, servindo de justificação a intenção da alma ${ }^{74}$. Em Novembro de 1158, seguramente perante a proximidade da morte, Urraca Rabaldes, viúva, na presença e com a ratificação de seu filho Álvaro Pais, confirma o que dera e vendera no território de Coimbra. Mantivera o seu usufruto, tudo transferindo agora para o mosteiro. Dessa alienação haviajá compensado seus filhos, doando-lhes as arras na vila de Mira e em outras partes. Faz também

" $\boldsymbol{L S}$ 122(carta de doação dos banhos régios ao arcediago Telo, feita por Afonso Henriques, em 9 de Dezembro de 1130); LS 123 (venda ao mesmo arcediago de um terreno na Ribela. pelo bispo de Coimbra D. Bernardo, em Junho de 1131); e $\boldsymbol{L S} 124$ (aquisição, por escambo com a igreja de S. Salvador, de um terreno junto aos banhos régios, depois de Março de 1133).

Mais precisamente, são dez outorgados por filhos de Rabaldo, um por seu genro Pedro Soares e outro por sua neta Elvira [Gonçalves].

${ }^{13}$ Veja-se, por todos, Saúl António Gomes, In limine conscriptionis. Documentos, chancelaria e cultura no mosteiro de Santa Cruz de Coimbra (séculos XII a XIV), Coimbra, 2000 (dissertação de doutoramento).

Cfr. nota 69. 
doação e venda de um terço de todas as herdades que possuía no território de Lafões (em Covelo, Campia, Paredes, Cambra, Santa Comba, Caveirós de Cima, Negrelos, Pinho, Estrada e Mourel), reservando para si, até à sua morte, os outros $2 / 3^{75}$. Ainda assim, o testamento de Rodrigo Pais, de Setembro de 1159, doava outros bens (além da vila de Oliveira de Frades, de metade de Quetriz e de casais em Pinheiro) que Fernando Martins (o filho de sua esposa que viria a ser bispo do Porto?) obtivera por doação régia em Alcabideque, Sujeira, Requeixada e Assamassa, mais o que tinham de património e compra em Lamasma, no território de Coimbra, mais apetecíveis para o mosteiro; por isso, esse testamento constitui o primeiro documento da Parte IV do Livro de D. João Teotónio, a dos "Testamentos dos Homens Seculares"76.

Este mesmo Livro, nesta mesma Parte IV, $\mathrm{n}^{\circ \mathrm{s}}$ IV, XXV e XXVII, recolhe testamentos de membros da geração seguinte da família, mais precisamente, dos filhos de Rodrigo Pais e Elvira Rabaldes. Estes testamentos foram ditados sobretudo pelo facto de um deles, Gonçalo Rodrigues, ter falecido intestado, pois foi morto pelos muçulmanos (occisus est a Sarracenis), entre Março de 1162 e Fevereiro de $1168^{77}$. Obviamente que Afonso Rodrigues, o primogénito, não deixa de recordar o muito auxílio recebido do mosteiro (promulto et bono adjutorio quod michi semper fecistis). Os irmãos de Gonçalo Rodrigues doam, por sua alma, dois casais com sua seara em Drizes (c. S. Pedro do Sul), em Lafões, e metade de uma vinha em Assamassa (c. Coimbra) ${ }^{78}$. Acrescente-se ainda o testamento de Sancha Rodrigues (feitojuntamente com seu cunhado Simão Pais), de Fevereiro de $1165^{79}$, por alma de seu marido Pedro Pais; a propriedade testada, em Cadima, é da herança do marido, pois a tem com Pedro Randulfes, seu tio, irmão da sua sogra Mor Randulfes.

São, porém, vendas de porções de património (sobretudo em Murtede, mas também em Alhadas e Raval) que fazem os filhos de Elvira Rabaldes e Rodrigo Pais (e de Elvira Rabaldes e Martim Pinioniz), entre 1162 e 1176. Nas II ${ }^{a}$, VIII $^{a}, X^{a}{ }^{a}$ e XIIII ${ }^{a}$ Partes das Cartas de Venda e Escambo, respectivamente, nos n. ${ }^{\circ}$ XXIII; XIX; XIV e XVI; e III, IV, V, inserem-se cartas de venda de Afonso Rodrigues e seus irmãos Fernando, Urraca e Sancha Rodrigues, e bem assim de Pedro e Paio Martins ${ }^{80}$.

75 TT- Santa Cruz, IV, 23.

${ }^{7}$ LDJT,fl. 55, doc. 65.

"Cfr., supra, notas 52 e 53.

${ }^{78}$ LDJT, fls. 64v.-65v., does. 89 e 91 (Fevereiro e Março de 1168).

${ }^{7}$ LDJT, fl. 56v, doc. 68 (...pro remedio viri mei Petri Pelaiz defuncti).

${ }^{80} L D J T$, fls. 137v-138, doe. 272; fls. 157v-158, doe. 320; fl. 158v, doe. 322; fls. 168-169, docs. 341-343. 
É óbvio que o interesse do mosteiro em arredondar o seu domínio, procurando comprar as várias partes do património fragmentado pelos diversos descendentes, impulsiona grande parte dessas vendas. No entanto, as necessidades destes cavaleiros em tempo de investidas dos muçulmanos não deixavam, por vezes, de se antecipar ao mosteiro, cuja ambição fica até facilitada, pois não raro acontece que um filho primogénito, a fim de se poder equipar devidamente com cavalo e armas para a guerra, vende a sua parte e a dos seus irmãos. Assim aconteceu em Março de 1162, com Afonso Rodrigues, que vendeu a herdade que lhe coube a ele, e a seus irmãos, de compra, património e avoenga, em Murtede, por 40 morabitinos (30, em dinheiro, e um cavalo). No entanto, promete compensar os irmãos com bens em outros locais ${ }^{81}$.

A pressão do mosteiro far-se-á sentir sobre as viúvas destes cavaleiros, como se depreende da carta de renúncia feita por Elvira Peres, viúva de Fernando Rodrigues, em Dezembro de 1191, muito pouco tempo depois da morte dele. Com o consentimento de seus tios, materno e paterno, Pedro Mendes e Ermígio Ramires, respectivamente, renuncia a favor do mosteiro, a quem o marido deixara seus bens, aos dons e arras que aquele lhe devia dar, disso absolvendo os respectivos fiadores. Além disso, deixa todo o haver móvel e imóvel que com ele adquirira, do Paiva ao Tejo, razão pela qual o mosteiro lhe deve dar 115 morabitinos pelas casas que ele deixou à Sé de Coimbra e 15 morabitinos pelos mouros que estão em penhor, dos quais o mosteiro deve ter a sua parte. Deve ainda perdoar- lhe as dívidas que ela fez com o marido, do Paiva ao Tejo, e, bem assim, as que ele fez do Paiva até além Douro ${ }^{82}$. Efectivamente, o Livro dos Aniversários da Sé de Coimbra atesta aquela doação de casas feita por Fernando Rodrigues, cujo óbito se regista a 16 de Novembro de $1191^{83}$. Do mesmo modo, sua irmã Sancha Rodrigues, na altura em que toma hábito em Santa Cruz, com o consentimento de sua filha e genro, faz doações a Santa Cruz, e, também, à Sé de Coimbra. O referido Livro dos Aniversários regista o seu óbito a 5 de Novembro de 1204, e a doação de uma vinha com seu olival em Assamassa ${ }^{84}$.

É curioso verificar que, tal como Urraca Rodrigues - que, em Novembro de 1174, com seu marido Martim Peres Clavo, tenta recuperar ao mosteiro de Santa Cruz a herdade de Tavares, qual solar de linhagem -, também Sancha

${ }^{s 1}$ LDJT, fl. 168, doc.341. Exceptua-se a parte dessa herdade que coube a seus meios irmãos, filhos de Elvira Rabaldes e Martim Pinioniz.

${ }^{82}$ LDJT, fls. 180v.-181, doc.362.

${ }^{s} \boldsymbol{L K}$, II, p. 252. As referidas casas, que confinavam com a adega do Cabido, ficavam na direcção da torre dos sinos e tinham um portal grande virado para as casas que foram do bispo de Lisboa.

${ }^{s t}$ LK, II, p. 239. 
Rodrigues, com sua filha Elvira Viegas e seu marido Martim Viegas de Podentes, entregam ao mosteiro, em Outubro de 1193, uma herdade em Alcabideque (c. Condeixa-a-Nova), uma almoinha e uma vinha em Coimbra,junto à Porta do Sol, o que tem em Raval e Alvade (c. Montemor-o-Velho), em Alhadas (c. Figueira da Foz) e em Lafões (dois casais em Mourel e dois em Moines) em troca do que o mosteiro tem em Podentes (c. Penela) e Traveira (c. Condeixa-a-Nova $)^{85}$. Era a cedência de parcelas longe do núcleo onde o casal habitaria, era o refazer desse núcleo com parcelas que haviam sido alienadas, era a consciência, num caso como no outro, de quanto cada uma daquelas propriedades, em si mesmas, ou integradas num conjunto, seriam estruturantes para cada uma das linhagens.

\section{Conclusão}

Iniciado o seu percurso e afirmação com o conde D. Henrique, a família dos Rabaldes apaga-se um pouco durante o governo de D. Teresa e de Fernão Peres de Trava (1121-1128). O apoio a Afonso Henriques na luta contra sua mãe e o subsequente protagonismo de Coimbra, reflectido no papel directivo que a cidade desempenha na Reconquista desde a década de 1130, faz a família recuperar poder e prestígio. Filhos e netos de Rabaldo frequentam a alcáçova régia e acompanham Afonso Henriques nas guerras ofensiva e defensiva, de Santarém e Lisboa ao Alentejo. Alguns perdem aí a vida. E com a perda da varonia rapidamente a linhagem desaparece.

A guerra, as funções militares na fronteira e a colaboração no repovoamento propiciam-lhes riqueza e a constituição de um pujante património. Outros almejam e logram mobilidade social e poder na carreira eclesiástica, no bispado do Porto, sob a sombra protectora do arcebispo de Braga, D. João Peculiar, seu parente.

As filhas de Rabaldo fazem bons casamentos, com cavaleiros do mesmo nível ou de superior posição social, proporcionando, assim, uma maior segurança à família. As boas posições desses esposos no xadrez político-militar ocasionam substanciais doações por parte do rei. Tanto a Rodrigo Pais, como a Paio Guterres da Silva ou a Afonso Pais (Oliveira de Frades, Quiaios, Nespereira). E muitas são as compras e escambos que Maria e Teresa Rabaldes fazem, com seus maridos.

Por presúria, compras e doações se constrói o património da linhagem; por múltiplas partilhas successórias, o mesmo se desagrega; enfim, por doações e vendas, no mosteiro de Santa Cruz de novo se reunifica. A guerra de fronteira que o ajudara a construir obriga, por vezes, à sua alienação. A mesma guerra,

"s AUC - Cofre, Caixa de Pergaminhos Avulsos, não numerados. 
matando também os genros de Rabaldo, propicia os recasamentos das suas filhas, cujo elevado grau de fertilidade gera uma fortíssima subdivisão do património e a sua progressiva desvalorização.

À semelhança de outras famílias de Coimbra, da mesma posição na mesma época, assinala-se a presença, nas várias gerações da linhagem, de importantes cavaleiros do exército régio, com funções militares ou administrativas (vigários, mordomos, juizes), e, simultaneamente, de outros com cargos eclesiásticos, nomeadamente bispos ${ }^{86}$ : Álvaro e Rabaldo Rabaldes, cavaleiros régios; Pedro Rabaldes, bispo do Porto; Fernando, Afonso e Gonçalo Rodrigues cavaleiros régios; seu meio irmão Fernando Martins, bispo do Porto.

Na Corte e na Igreja se construíram, pois, alguns percursos familiares que a documentação régia ou a eclesiástica nos foi revelando e permitiu reconstituir. Porque na Corte ou na Igreja exerceram cargos. Porque na Corte receberam bens e mercês, e na Corte combinaram casamentos. Porque à Igreja doaram ou venderam bens, e pela Igreja foram rememorados.

${ }^{86} \mathrm{Na}$ família dos Anaias, Martim Anaia (1132-1176)- filho de Anaia Vestrariz (1108-1130) foi um importantíssimo cavaleiro de Coimbra, do mesmo modo que seu cunhado Gonçalo Dias (casado com Maria Anaia), foi alcaide de Coimbra (1126-1137, a quem sucedeu Rodrigo Pais, genro de Rabaldo); por seu lado, seu irmão João Anaia, depois de ter sido prior, foi bispo de Coimbra, entre 1147 e 1155; e, se não é seu sobrinho-neto, é decerto seu parente o Pedro Salvadores que foi bispo do Porto (1236-1247). 


\section{Apêndices Biográficos ${ }^{87}$}

\section{Rabaldo (1102-1117)}

Presente no território de Coimbra entre 1102 e 1117, foi vigário do conde D. Henrique na cidade de Coimbra (1109) e detentor de poder na terra de Lafões ao tempo de D. Teresa (1117). Terá casado, talvez, com uma dona da terra de Lafões de quem teve sete filhos: Álvaro Rabaldes, Elvira Rabaldes, Maria Rabaldes, Pedro Rabaldes, Rabaldo Rabaldes, Teresa Rabaldes e Urraca Rabaldes. Por presúria, doação e/ou compra, e talvez por casamento, deteve algumas villae ou partes de villae nos territórios de Montemor-o-Velho e Santa Eulália (Arazede, Treixede, Lamasma e Santa Eulália), em Cantanhede (Murtede, Enxofães), Anadia (Aguim) e Coimbra (Alvade, Raval e Fontoura). Do mesmo modo, deteve vilas, casais ou herdades na terra de Lafões, em Arcozelo, Tabuadelo, Pinho, Manhouce, Pindelo, Drizes, Moure, Covelo, S. Martinho das Moitas, Negrelos, Estrada (c. S. Pedro do Sul) Pinheiro de Lafões (c. Oliveira de Frades), Campia, Cambra, Cercosa, Santa Comba, Paredes, Caveirós de Cima (c. Vouzela).

Fontes: LP 377 (1102 Maio 1); LP 59 (1109 Jul. 29); LP405 (1113 Abril); ;5211(1113 Abril 8); $i^{\wedge} 235$ (1117 Abr. 8).

\section{Álvaro Rabaldes (1128-1141)}

Cavaleiro de Afonso Henriques, testemunha, como autoridade ou como proprietário na terra de Lafões, alguns actos daquele rei, entre 1128 e 1141, só ou juntamente com seu irmão Rabaldo Rabaldes. Ao lado dos milites de Mamei terá apoiado o infante Afonso Henriques contra sua mãe D. Teresa e Fernão Peres de Trava. Em conflito com a Sé de Coimbra, destruiu a igreja de Vila Cova, o que viria a compensar com uma propriedade no território de Coimbra, em Janeiro de 1133. Dividido entre as duas zonas de implantação da família, ora o encontramos vendendo herdades em Treixede (c. Montemor-o-Velho) antes de Agosto de 1139, ora testemunhando a carta de couto do mosteiro de Sever do Vouga, em 11 de Novembro de 1141. Segundo o Livro de Linhagens teve pelo menos uma filha, Maria Álvares, que casou com Nuno Gomes Guedão, de onde sairão os Ribeiros.

Fontes: LP 63 e 479 (1128 Dez 4 ); DR 95 (1128 Dez 4); DR 440 (1133 Jan); LS 141 (1139 Ag.); DR 188(1141); LD 6T6.

${ }^{87}$ Pretende-se, com estas microbiografias, deixar, em síntese e reunidos, os elementos sobre cada membro da família que ficaram, atrás, dispersos pelo texto. Depois de Rabaldo, os seus filhos serão apresentados por ordem alfabética e, dentro de cada um, se irão referindo os respectivos cônjuges e filhos (e, às vezes, netos). As fontes (só as manuscritas, inéditas ou publicadas) serão apresentadas no final de cada biografia. 


\section{Elvira Rabaldes (1115-1159)}

Começa a aparecer na documentação, já viúva ou separada de seu primeiro marido, Martim Pinioniz, de quem teve: Pedro Martins, Paio Martins, Fernando Martins (bispo do Porto) e Teresa Martins.

Casou uma segunda vez com Rodrigo Pais, cives Colimbrie, alcaide de Coimbra (1137-1157) e de Lisboa (1158), de quem teve: Afonso Rodrigues, Fernando Rodrigues, Urraca Rodrigues, Sancha Rodrigues e Gonçalo Rodrigues. Em Março de 1146 vende a Santa Cruz a sua porção de Aguim, que tinha da parte da mãe, em troca do voto de Santiago que o mosteiro lhe dera durante um ano. Aparece frequentemente com seu marido Rodrigo Pais (nomeadamente em 1147, 1149 e 1159) fazendo doações ao mosteiro de Santa Cruz, onde se mandam sepultar, de bens que têm de património e matrimónio, de ganho ou de doação régia, tanto no território de Coimbra como no de Lafões. Por compra obteve Arazede (c. Montemor-o-Velho) e Podentes (c. Penela). Tinha ainda bens em Carnide (c. Pombal).

Fontes: DR 194 (1142 Ab.); TT-Santa Cruz, II, 39 (1145 Set.); LS 136 (1146 Março); LS 12 (1147 Out.); TT-Santa Cruz, III, 20 (1149 Maio); LS 28 [1139-1154]; LS 47 (1147 Out.); DR 224 (1147 Nov. 1); LDJT, fl. 55-55v, doc. 65 (1159 Set.); Sé de Coimbra, cx. 27, rolo 3, doc. 21. Para Rodrigo Pais, enquanto alcaide de Coimbra: $L S$ 13, 102, 118,125,197; DR 232, 234, 235, 239, 240, 242, 246, 247, 251,257; alcaide de Lisboa: DR 257, 268, 269. Para os filhos de Elvira e Martim Pinioniz: LDJT, fls. 70-70v, doe. 104 (1169 Abr.), fls. 168-169, docs. 341 -343 (1162-1170), TT- Sé de Viseu, IV, 11 e 23 (1171 Nov. 14 e 1176 Abr.); TT- Tarouquela, IV (1185 Março); Censual do Cabido da Sé do Porto, pp. 385 e ss.. Para os filhos de Elvira e Rodrigo Pais: DR 257 [1156-1157], 280 (1162 Março), 285 (1163 Fev.); LDJT, fls. 20v-22.doc 14, fl. 65-65v (1162 Março), fl. 168, doc. 341 (1162 Março);TT-Santa Cruz, VI, 10 (1165 Fev.), VII, 7 (1168 Fev.), VII, 9 (1168 Março), VIII, 20=LDJT, fl. 157v (1173 Ag.); LDJT, fls. 137v-138 (1174 Nov.); LDJT, fl. 97v, doc. 177 (1175 Julho), fl. 158v (1176 Abril); S. Jorge de Coimbra, m. IV (s. d.); TT-Santa Cruz, m. XIV, doc. 37, s.d.; AUC - Cofre, Caixa de Pergaminhos Avulsos, não numerados; LK, II, pp. 239 e 252.

\section{Maria Rabaldes (c. 1115-1147)}

Nascida no início do século XII, casou uma primeira vez, antes de 1115, com Gonçalo, de quem teve um filho e uma filha, Elvira [Gonçalves]. Está já casada segunda vez, a 16 de Julho de 1129, com Pedro Soares de Grijó (1104-1136), de quem teve Afonso, Paio, Urraca e Teresa Peres. Por sucessivas vendas, transfere para o mosteiro de Santa Cruz os bens que tem, de parentela, em Aguim (c. Anadia) (em Abril de 1134), em Alvade e Raval (em Agosto de 1140), em Lamasma, Arazede, Santa Eulália e Quinhendros, no termo de Santa Eulália (em Abril de 1142) e, finalmente, os que tinha em Treixede (em Junho de 1143). Tinha também bens em Cambra, de que seria entregue uma parte a Santa Cruz,juntamente com uma parte de Murtede, se seus filhos não aceitassem a doação de toda a sua parte de Murtede (Março de 1147). 
Seu marido Pedro Soares, em Junho de 1133, vendera a herdade que recebera dela e da filha Elvira Gonçalves em Murtede, tendo mais tarde surgido conflito entre os filhos dele e o mosteiro, pelo que este, em Dezembro de 1146, deu 12 morabitinos aos filhos dele e de Maria Rabaldes. Desconhecem-se os casamentos e a descendência dos filhos de Maria Rabaldes. Sabe-se, no entanto, que, em Outubro de 1177, Elvira Gonçalves tinha já um filho.

Maria Rabaldes morre depois de Março de 1147, altura em que testa alguns bens a Santa Cruz e pede para aí ser sepultada.

Fontes: TT- Santa Cruz, I, 19 ; Baio Ferrado de Grijó, doc. 298 (1129 Jul. 16); LS 133 (1134 Abr.), LS 127(1140 Ag.), LS 128 (1142 Abr. 1), LS 129 (1143 Jun.), LS 16 (1147 Março). Para o marido Pedro Soares: TT- Santa Cruz, m. I, doe. 19 (1133 Jun.); Baio Ferrado de Grijo, docs. 7, 11, 17, 24, 101, 298 (1129-1136). Para sua filha Elvira Gonçalves: TT- Santa Cruz, 1, 19 (1133 Jun.); II, 39 (1145 Set.); III, 5 (1146 Dez.); LS 135 (1145 Nov.); LDJT, fl. 153-153v, doc. 308 (1158 Ag.), 167v, doc. 340 (1160 Jul.).

\section{Pedro Rabaldes (1133-1145)}

Cónego, pelo menos, desde 1135, foi bispo do Porto entre 1138 e 1145. Começa a aparecer na documentação em Abril de 1133, fazendo uma convenção com o mosteiro de Santa Cruz sobre a porção que tinha na vila de Murtede, e, tal como seus irmãos, vendendo metade de um casal que tinha, de parentela, em Aguim. Em $\mathbf{2 6}$ de Outubro de 1137, logo após o bispo do Porto, D. João Peculiar, confirma a carta de isenção de jurisdição episcopal concedida ao mosteiro de Grijó. No Verão de 1138 está presente em documentos sobre concessões a Santa Cruz de bens no concelho de Anadia. Desde Março de 1139, já como bispo do Porto, aparece frequentemente na documentação de Afonso Henriques, pelo menos na ligada ao mosteiro de Santa Cruz.

Além dos bens já referidos em Aguim, herdou, tal como seus irmãos, bens em Lamasma, Eimede, Santa Eulália, Maiorca, Arazede, Treixede, Reveles, Murtede, Enxofães, Alvade e Raval, cuja porção vende ao mosteiro de Santa Cruz, em Dezembro de 1140, em troca de 70 dinheiros em ouro que os cónegos lhe haviam emprestado. Destas mesmas herdades entrega, antes de 29 de Julho de 1145, a porção de seu irmão Rabaldo Rabaldes, recém-falecido e do qual era testamenteiro. Teria também bens no c. de S. Pedro do Sul, mais precisamente em Negrelos, dos quais doa 4 casais à Sé do Porto, que ainda os possuía em 1258, aquando da realização da Inquirições.

Fontes: Baio Ferrado de Grijó, doc. 5 (1137 Out. 26); TT-Sé de Coimbra, cx. 27, rolo 2, doc. 11; LS 134 (1135 Fev); LS 31 (1138 Jun.) e LS 18 (1138 Ag.); LS 126 (1140 Dez); LS 9-12 (1139-1142); LS 16 e 225 (1147 Março); Censual do Cabido da Sé do Porto, p. 383; Sérgio Lira, O Mosteiro de S. Simão da Junqueira, Porto, 1993 (dissertação de mestrado), vol. II, doc. 92 (1145 Fev.).

\section{Rabaldo Rabaldes (1109-1144)}

Filho primogénito de Rabaldo, nascido talvez à volta de 1095, integra-se desde cedo no séquito do conde D. Henrique, onde começa a aparecer, com seu pai, em 1109. 
Pertenceu depois, tal como seu irmão Álvaro Rabaldes, ao grupo dos cavaleiros de Afonso Henriques, de Viseu ou de Lafões. Como baron ou miles de Lafões e proprietário na região, testemunha, em Dezembro de 1137, um escambo em que o mosteiro de Santa Cruz cede uma herdade em Moçâmedes (c. Vouzela) em troca de uma vinha em Vale Meão (c. Coimbra). Herdado, como seus irmãos, em Murtede e em Enxofães, vende a Santa Cruz as suas porções, em Junho de 1138, por 50 morabitinos.

Morre antes de 29 de Julho de 1145, data da morte de seu irmão Pedro Rabaldes, que, na qualidade de seu testamenteiro, entrega bens que ele tinha em Lamasma, Arazede, Santa Eulália e Tavarede, porque lhos encomendara à hora da morte e porque devia ao mosteiro 12 morabitinos.

Fontes: $\boldsymbol{L P} 59$ (1109 Jul. 29); $\boldsymbol{L P} 63$ e 479 (1128 Dez 4 ); DR 95 (1128 Dez 4); $\boldsymbol{L} 215$ (1137 Dez); LS 131 (1138 Junho); LS 16 (1147 Março) e 225 (a data deste documento deverá ser corrigida para [a.1145 Julho 29]).

Teresa Rabaldes (a. 1115-1138)

Casou duas vezes, uma primeira, antes de 1115, com Gonçalo Gonçalves (1115-1123), e uma segunda, por 1130 ou 1131, com Afonso Pais [de Paiva] (a. 1116-1141), não sendo conhecidos filhos de nenhuma das uniões.

Com seu primeiro marido comprou bens em Negrelos (onde tinha outros de herança) e Arcozelo, e escambou bens em Segadães por outros em Tabuadelo, e bens em Bendavizes por outros em Arcozelo. Nesta mesma villa recebem outros bens, por encomendação. Finalmente, compram outros em Souto de Lafões, Paredes do Gravo, Sequeiró (c. Oliveira de Frades) e em Fiais e Cercosa (c. Vouzela).

Em Janeiro de 1130 estará já casada com Afonso Pais (que fora vassalo de D. Teresa, de quem recebera metade do castelo de Benviver), que nessa data confirma a doação de metade de Quiaios feita por Afonso Henriques a Paio Guterres e Urraca Rabaldes. Em 30 de Março de 1131 recebem de Afonso Henriques, talvez como dote de casamento, Nespereira (c. Cinfães) e, antes de 4 de Junho de 1133, uma herdade em Bassim (fr. France, c. Viseu). Em Março de 1138, na presença do marido, doa à igreja de S. João de Coimbra, onde se quer sepultar, um quinto dos bens que possuía da parte de seu pai e sua mãe, e dos que havia ganho com seu marido Gonçalo Gonçalves (em Tabuadelo, Arcozelo, Negrelos, Mourel e Covelinho), bem como em Pinheiro (que trocara com seu segundo marido, por Ordiais), em Taveirós e Cambra, Paredes, Campia, Cercosa, Covelo e Manhouce e, ainda, em Murtede, Treixede, Lamasma e Arazede e no Campo de Coimbra e, finalmente, o quinto da sua corte em Coimbra. Quanto ao que ganhou com seu segundo marido, ele manteria o usufruto e, após a sua morte, entregaria, da parte dela, um quinto.

Teresa Rabaldes tinha o seu magister, o clérigo Soeiro.

Fontes: DP, III, 510 (1115 Jul. 13); DP, IV, 28 (1116 Dez. 14), 86 e 87 (1119 Jan. 6), 92 (1119 Abr, 21), 116 (1120 Fev.), 301 (1122 Dez. 20), 331 (1123 Março 18); DR 65, 105,110 e 115 (de Julho e Dezembro), 116 (1131 Março 30); TT-Sé de Viseu, m. II, doc. 19; 
DR , II, ref. ${ }^{\circ}$ 34; LP 309 (1138 Março). Para Gonçalo Gonçalves: DP, III, 510 (1115 Jul. 13); DPIV,5e7(1116 Março 19 e 1116 Abril 8); LP 235 (1117 Jul.), 241 (1123 Out. 10) e 579 (1123 Jan. 25). Para Afonso Pais: DP, IV, 22 (1116 Out..); DR 95 (1128 Dez. 4), 105 (1130 Jan.), 110 (1130 Jul. 12), $115(1130$ Dez. 9), 188(1141 Nov. 11)

\section{Urraca Rabaldes (1130-1158)}

Aparece na documentação desde Janeiro de 1130, já casada com Paio Guterres [da Silva] (1095-1139), alcaide do castelo de Santa Eulália, no momento em que Afonso Henriques lhes doa 1/2 de Quiaios (c. Figueira da Foz). Em 1134, entregam a Santa Cruz essa metade de Quiaios (vendem $1 / 4$ por 150 morabitinos e doam o restante). Em Setembro de 1136 doam a igreja desta villa. Em Julho de 1139, com o consentimento de seu marido (auctoritate mei mariti Pelagii Gotierriz), Urraca Rabaldes vende a Santa Cruz as herdades que tinha, de património, em Raval e Alvade (c. Coimbra), Lamasma, Santa Eulália (c. Figueira da Foz), Arazede e Treixede (c. Montemor-o-Velho), Enxofães e Murtede (c. Cantanhede) e que já haviam entregue ao mosteiro, em penhor, por 62 morabitinos. Em Agosto de 1148, já viúva, vende ao mosteiro, por dois morabitinos de ouro, o que tinha, da parte de sua mãe, em Aguim. Em 28 de Outubro de 1154 compra a Pedro Viegas e sua mulher Mor Afonso um casal em Ordiais (Ordealis) por 2 morabitinos de ouro e uma pele. Finalmente, em Novembro de 1158, doa e vende ao mosteiro de Santa Cruz $1 / 3$ de todas as herdades que tem no território de Lafões (1/4 da vila de Covelo, 1/8 de Campia, 1/8 de Paredes, 1/8 de Cambra, 1 casal em Santa Comba, 1 casal em Caveirós de Cima, 1 casal em Negrelos, 2 casais em Pinho, 1 casal em Estrada, 1 casal em Mourel), reservando o usufruto dos outros $2 / 3$ até à sua morte. Confirma ainda todas as herdades que já deu e vendeu no território de Coimbra, cujos frutos até agora recebia e que passarão para o mosteiro, e de cujas herdades já compensou os seus filhos, doando-lhe as suas arras na vila de Mira e outras partes. O preço da parte que vendeu em Lafões foi 1 mula (avaliada em 40 morabitinos), uma moura (avaliada em 10) e 1 manto (avaliado em 4). Este documento foi louvado e confirmado por seu filho Álvaro Pais, que estava presente e vende e doa ao mosteiro quanto lhe havia de vir de sua mãe nesses 2/3 de Lafões. Segundo o Livro de Linhagens do Conde D. Pedro, que omite este filho, o casal teria tido uma filha, Goncinha Pais (1144-1160) que casou com Mem Afonso de Refóios, vassalo de Afonso Henriques (1128-1160) e tenente do castelo de Arouce, de quem teria tido Garcia Mendes de Parada.

Fontes: $L L$ 58H2; LS 177 (1134 Nov.), LS 10, 125 e 137; TT-Santa Cruz, I, 30 (1134 Nov.); IV, 3; IV, 23. Para seu marido Paio Guterres: DR 5(1097 Dez. 9), 96 (1129 Março 14), 105 (1130 Jan., considerado falso), 123 (1132 Fev. 16), 146 (1134 Nov.), 141 (1135 Maio 17), 148(1135 Maio 18), 151 (1136 Março 25), 156 (1136 Nov.), 158(1137 Jun.), 161 (1137 Set.), 168 (1139 Março), 171 (1139 Jun.), 172 (1139 Jun.), 182(1141 Fev.12); TT-Santa Cruz, I, 30 (1136 Set.): LS 176 (1141 Maio). Para seu filho Álvaro Pais: TT-Santa Cruz, IX, 30 (1176 Fev.): LDJT, fl. 129-129v, doc. 253. 


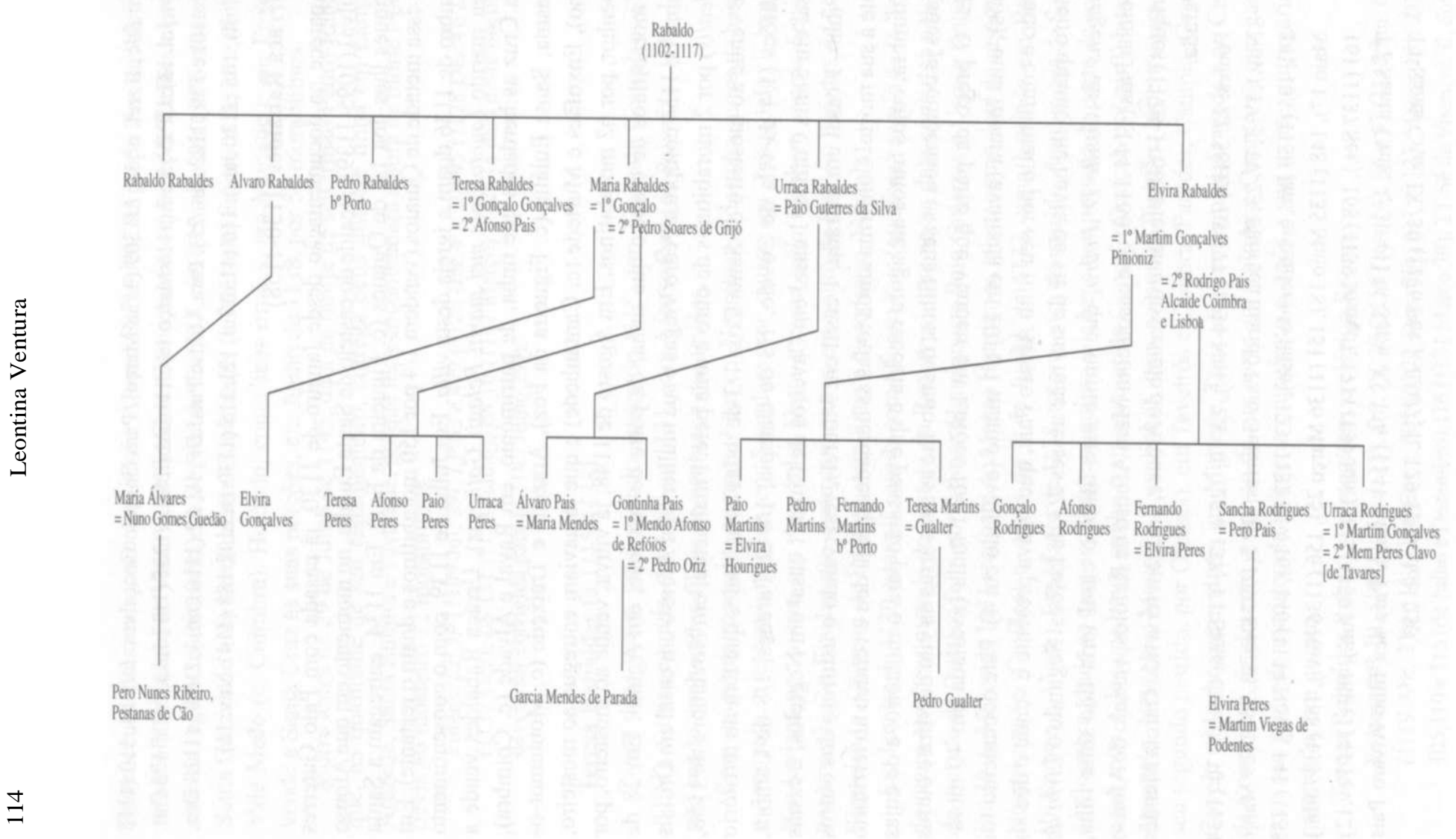

